\title{
X-ray Photoelectron Spectroscopy Study of Cobalt Supported Multi-walled Carbon Nanotubes Prepared by Different Precursors
}

\author{
Jeong-Min Lee', Ju Wan Kim¹, Ji Sun Lim', Tae Jin Kim², \\ Shin Dong Kim ${ }^{1}$, Soo-Jin Park ${ }^{3}$ and Young-Seak Lee ${ }^{1, \AA}$ \\ ${ }^{1}$ Dept. of Nanotechnology, Chungnam National University, 305-764, South Korea \\ ${ }^{2}$ Core Technology Research Center for Fuel Cell, Jeonbuk Techno-park, Jeonbuk-do, 561-350, Korea \\ ${ }^{3}$ Dept. of Chemistry, Inha Univ., 253, Nam-gu, Incheon 402-751, Korea \\ ^e-mail: youngslee@cnu.ac.kr \\ (Received May 25, 2007; Accepted June 19, 2007)
}

\begin{abstract}
The effect of cobalt precursor on the structure of Co supported multi-walled carbon nanotubes (MWCNTs) were studied by using X-ray photoelectron spectroscopy (XPS). MWCNTs were treated with a mixture of nitric and sulfuric acids and decorated with cobalt and/or cobalt oxides via aqueous impregnation solutions of cobalt nitrate or cobalt acetate followed by reduction in hydrogen. XPS was mainly used to investigate the phase of cobalt on MWCNTs after reduction with $\mathrm{H}_{2}$ flow at $400^{\circ} \mathrm{C}$ for $2 \mathrm{~h}$. Higher cobalt-nanoparticle dispersion was found in the MWCNTS prepared via cobalt nitrate decomposition. A typical XPS spectrum of Co 2p showed the peaks at binding energy (BE) values equal to 781 and $797 \mathrm{eV}$, respectively. It is found that cobalt nitrate supported MWCNTs is more dispersive and have catalytic activity than that of cobalt acetate supported MWCNTs at same preparation condition such as concentration of precursor solution and reduction environment.
\end{abstract}

Keywords : Cobalt, Catalyst, Decoration, XPS, MWCNTs

\section{Introduction}

The discovery of synthetic methods to produce carbon nanotubes (CNTs) [1], structurally built of graphene cylinders, opened the possibility of research opportunities for a variety of applications [2-5]. Different studies have shown the excellent potential of CNT as sensitive material for detecting biological and chemical molecules [6-8]. Via functionalization of CNT side walls, an improved interaction between a specific chemical species and the nanotube can be reached and the selectivity of the adsorption process can be enhanced [9]. Some properties of CNTs make them very attractive to produce small, wearable sensors for industrial and transport environments.

MWCNTs have been promising nanomaterials for the commercial applications because of mass production. As an alternative to the usual functionalization techniques that are used to increase the reactivity of the CNT surface, CNT can be decorated with metal nanoparticles. For example, Pd decorated CNTs become sensitive to $\mathrm{H}_{2}$ [10]. Metal clusters have a broad range of diverse structures and can provide a wide range of reactivity with different species [11]. The concept of using CNTs decorated with metal clusters as the sensitive material of a device where the metal cluster surfaces act as reactive sites for the adsorption of the target molecules has been introduced recently in a theoretical study
[11]. According to these preliminary theoretical results, CNTs decorated with metal clusters could be tailored for the recognition of chemical species with high sensitivity and selectivity. The key concept is to use nano-clusters (small size is essential to maximize the effect of adsorbates on metallic clusters) that donate or accept a significant amount of charge upon adsorption of a target molecule, so that electron transport in the nanotube is affected [12, 13].

Heterogeneous catalysis is founded on reactions happened at active sites on the surface of them [14]. This reaction procedure includes that adsorption, surface diffusion, chemical arrangements of the intermediates and desorption of the products. These factors are functions of electromagnetic properties and the numbers of catalytic sites. Therefore, it is important to investigate the changes of electric and chemical properties of the surface of catalysts.

Guczi et al. reported that Co or Fe impregnated MWCNTs showed higher catalytic activity for CO hydrogenation than deposition of pre-prepared metal oxide nanoparticles onto the MWCNTs support [15]. Yin et al. showed that CNTsupported metals are active in hydrogen generation from ammonia and that the CNT supported Ru exhibited the highest efficiency in the reaction [16].

However, there are few papers on the study on both the decoration and reduction with metals, especially, such as cobalt nanoparticles. Although several reviews on Co sup- 
ported catalysts are available $[17,18]$, in this paper more recent topics in this field is covered with an emphasis on the surface property of Co supported MWCNTs using X-ray photoelectron spectroscopy (XPS).

In order to investigate the effect of cobalt precursor on the structure of Co supported MWCNTs, we decorated cobalt and/or cobalt oxides on MWCNTs by impregnation method with two different precursors such as cobalt nitrate and cobalt acetate. X-ray photoelectron spectroscopy (XPS) was mainly used to investigate the phase of cobalt on MWCNTs.

\section{Experimental}

\subsection{Preparation of MWCNTs}

MWCNTs were prepared by the vapor-grown method using acetylene $\left(\mathrm{C}_{2} \mathrm{H}_{2}\right)$ as carbon source and ironpentacarbonyl $\left(\mathrm{Fe}(\mathrm{CO})_{5}\right)$ as catalyst [19]. The nanotubes used in this study are under $20 \mu \mathrm{m}$ long, and outer and inner diameters are $60-80 \mathrm{~nm}$ and $30-50 \mathrm{~nm}$, respectively. In order to remove the impurities like metal and soot from MWCNTs and provide functional groups such as $-\mathrm{COOH},-\mathrm{OH}$ and -CO, etc. on the MWCNTs surface, MWCNTs powder was immersed in the mixture of $12 \mathrm{~N} \mathrm{HNO}_{3}$ and $12 \mathrm{~N} \mathrm{H}_{2} \mathrm{SO}_{4}$ solutions. These solutions were boiled for $5 \mathrm{~h}$ under refluxing conditions. After boiling, these solutions were filtered with a membrane filter and sufficiently washed by deionized water. MWCNTs obtained by filtration were dried at $383 \mathrm{~K}$

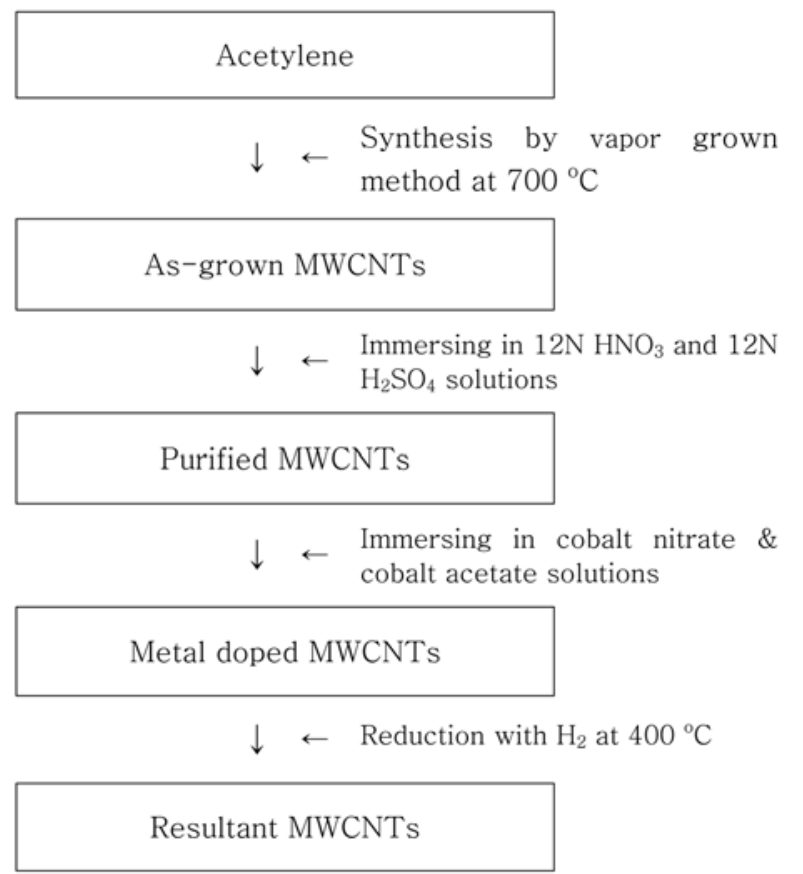

Fig. 1. The schematic diagram of experimental procedure for MWCNT used in this study. for $2 \mathrm{~h}$ under air. Fig. 1 was the schematic diagram of experimental procedure for MWCNT used in this study. The details of the experimental procedure were given elsewhere [20].

\subsection{Preparation of Cobalt supported MWCNTs}

In order to disperse cobalt particles on MWCNTs, $0.5 \mathrm{~g}$ of MWCNTs treated with acids was immersed into $65 \mathrm{mM}$ cobalt nitrate and cobalt acetate solutions of $20 \mathrm{ml}$, respectively. These solutions were sonicated for $1 \mathrm{~h}$ at room temperature for good dispersion. Each sonicated solution was evaporated in oil evaporator until solution was perfectly vaporized. After vaporization, vaporized powder was dried at $383 \mathrm{~K}$ overnight. Then, the samples were reduced in flowing $5 \% \mathrm{H}_{2} / \mathrm{Ar}$ as the reducing gas, during which reduction conditions were first heated at $5 \mathrm{~K} / \mathrm{min}$, and kept at $673 \mathrm{~K}$ for $2 \mathrm{~h}$. Reduction temperature was chosen because Zhang et al. suggested that cobalt oxides was reduced over $623 \mathrm{~K}$ [21].

\subsection{Characterization and analysis}

In order to just observe the particle and wall thickness of MWCNTs decorated with cobalt, field emission transmission electron microscopy (FE-TEM), was used (JEOL model JEM-2100F). The XPS spectra were obtained with MultiLab 2000 spectrometer (Thermo electron corporation, England) to the changes of chemical species on the surface of MWCNTs before and after cobalt decoration. Al K $\alpha$ (1485.6 $\mathrm{eV}$ ) was used as X-ray source at $14.9 \mathrm{keV}$ of anode voltage, 4.6 $\mathrm{A}$ and $20 \mathrm{~mA}$ as filament current and emission current, respectively. Each sample was treated at $10^{-9}$ mbar to remove impurities. The survey spectra were obtained at 50 $\mathrm{eV}$ of pass energy and $0.5 \mathrm{eV}$ of step size. Core level spectra were also obtained at $20 \mathrm{eV}$ and $0.05 \mathrm{eV}$ as pass energy and step size, respectively.

\section{Results and Discussion}

Fig. 2 shows the morphology of the MWCNTs before and after cobalt decoration with nanoparticles. Cobalt particles were well dispersed on the surface of MWCNTs. The loading amount of cobalt particles depended on the concentration of precursor solution. This was in good agreements with the previous reports $[8,9]$. As shown in Fig. 2, compared to 15 wt $\%$ Co-MWCNTs, the surface of $25 \mathrm{wt} \%$ Co-MWCNTs was almost covered with cobalt particles. The thickness of cobalt particles is nearly $30 \mathrm{~nm}$. Also, there is a lump of cobalt particle, which may prevent the adsorption of gas due to decreasing the available active sites. Kim et al. [8] reported that MWCNTs covered with $6 \mathrm{wt} \% \mathrm{Ni}$ particles show well-dispersed Ni particles as small as $\sim 1.2 \mathrm{~nm}$, while 

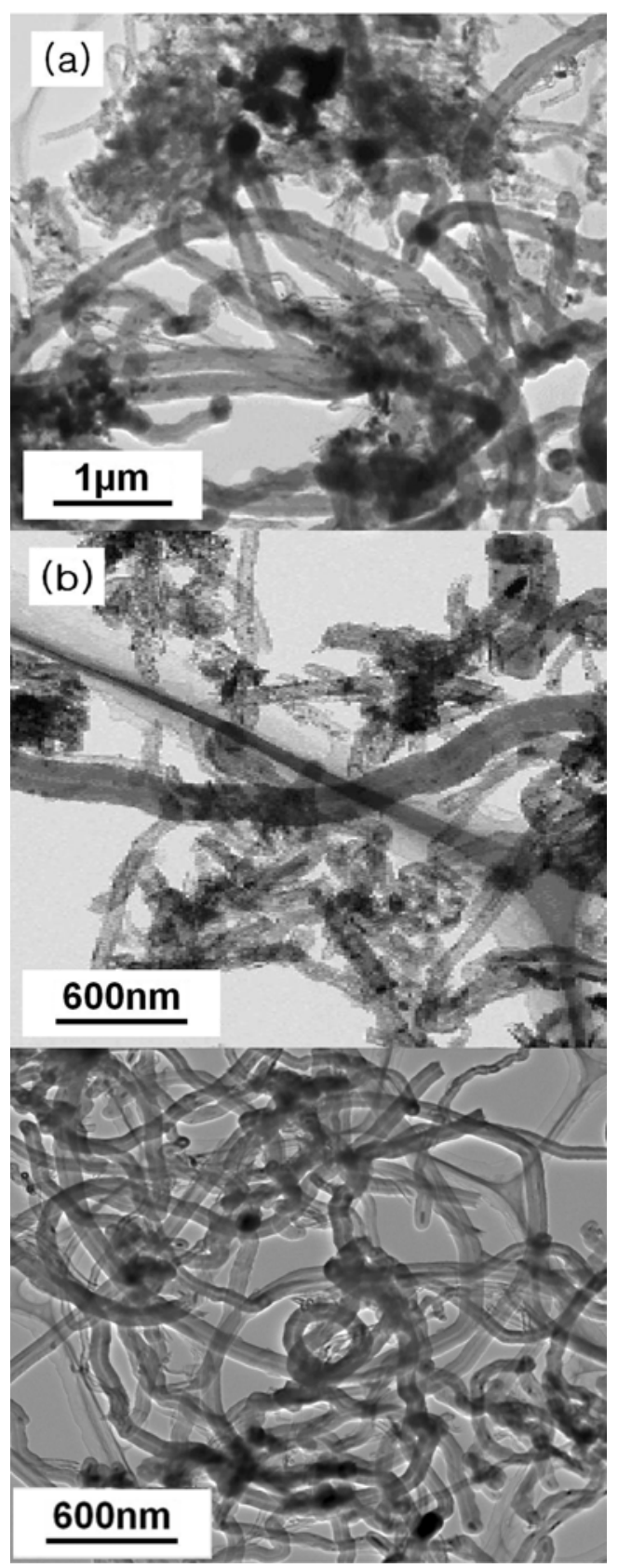

Fig. 2. TEM images of (a) $15 \mathrm{wt} \%$ Co-MWCNTs, (b) $25 \mathrm{wt} \%$ Co-MWCNTs obtained from cobalt acetate and (c) acid-treated MWCNTs.

nickel particles of Ni-MWCNTs containing both 13 and 40 wt $\%$ nickel metal are larger than that of $6 \mathrm{wt} \% \mathrm{Ni}-$ MWCNTs.

In case of cobalt supported MWCNTs, It is believed that similar results could be observed. Considering the CoMWCNTs for gas adsorption materials from the viewpoint of accessible active site, $15 \mathrm{wt} \%$ Co-MWCNTs will be more efficient than $25 \mathrm{wt} \%$ Co-MWCNTs due to the decrease of adsorption sites. So, in this study, we chose the MWCNTs

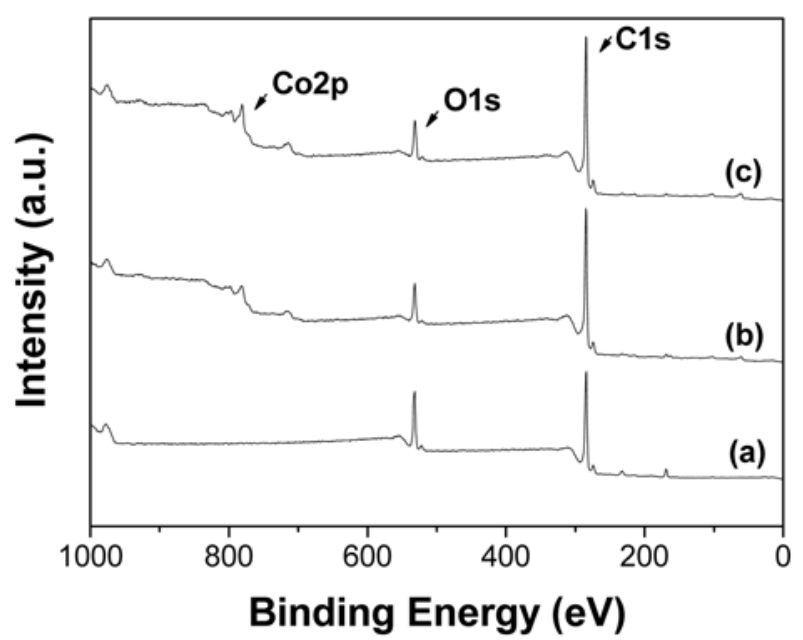

Fig. 3. XPS wide scan spectra of Acid-MWCNTs (a); Co-AMWCNTs (b); Co-N-MWCNTs (c).

with $15 \%$ concentration of both cobalt nitrate and cobalt acetate solution

XPS spectra of cobalt supported MWCNTs prepared by different precursor and acid treated MWCNTs (AcidMWCNTs) are shown Fig. 3. The survey spectra in the 0$1000 \mathrm{eV}$ of binding energy range were investigated to identify the elements on the surface of samples and perform a quantitative analysis.

All of the survey spectra show distinct carbon and oxygen peaks at around $284.5 \mathrm{eV}$ and $532.0 \mathrm{eV}$, respectively. And Co2p peaks were also found cobalt supported MWCNTs based on cobalt nitrate (named as Co-N-MWCNTs) and cobalt acetate (named as Co-A-MWCNTs). Relatively small peaks of survey spectra represent minor elements such as nitrogen and sulfur. As shown in Fig. 3, the broad peaks around $700 \mathrm{eV}$ indicate Auger electron peaks of cobalt. The atomic ratio and binding energy of all elements on the surface of MWCNTs were listed in Table 1. The binding energies of all peaks were corrected as compare with reference peak $(\mathrm{C} 1 \mathrm{~s}, 284.5 \mathrm{eV})$ [22]. Real position of $\mathrm{C} 1 \mathrm{~s}$ peaks of each samples were $284.35 \mathrm{eV}, 284.48 \mathrm{eV}$ and $284.46 \mathrm{eV}$ corresponding to the acid-MWCNTs, Co-A-MWCNTs and Co-N-MWCNTs, respectively. The carbon concentration of the surface of each MWCNTs were 70.6 at\% (AcidMWCNTs), 84.57 at\% (Co-A-MWCNTs) and 84.31 at $\%$ (Co-N-MWCNTs). The O1s peak positions of cobalt supported MWCNTs prepared by both precursors were shifted to lower binding energy level. Atomic ratio of cobalt supported Co-N-MWCNTs were 1.3 times bigger than those of Co-A-MWCNTs. As shown in Table 1, there are no cobalt peaks on only acid-treated MWCNTs. In spite of heat treatment at $673 \mathrm{~K}$, It was found that acid-treated MWCNTs contained S2p of 3.07 at.\%. It has implied that sulfur compounds formed from sulfuric acid treatment was not thoroughly removed during heat treatment because sulfur 
Table 1. XPS surface element analysis data of acid treated- and cobalt supported MWCNTs

\begin{tabular}{lcccccccccc}
\hline & \multicolumn{2}{c}{$\mathrm{C} 1 \mathrm{~s}$} & \multicolumn{2}{c}{$\mathrm{O} 1 \mathrm{~s}$} & \multicolumn{2}{c}{ Co2p } & \multicolumn{2}{c}{ S2p } & N1s \\
\cline { 2 - 11 } Samples & $\begin{array}{c}\text { Atomic } \\
\text { percent } \\
(\text { at\% })\end{array}$ & $\begin{array}{c}\text { Binding } \\
\text { energy } \\
(\mathrm{eV})\end{array}$ & $\begin{array}{c}\text { Atomic } \\
\text { percent } \\
(\mathrm{at} \%)\end{array}$ & $\begin{array}{c}\text { Binding } \\
\text { energy } \\
(\mathrm{eV})\end{array}$ & $\begin{array}{c}\text { Atomic } \\
\text { percent } \\
(\text { at\% })\end{array}$ & $\begin{array}{c}\text { Binding } \\
\text { energy } \\
(\mathrm{eV})\end{array}$ & $\begin{array}{c}\text { Atomic } \\
\text { percent } \\
\text { (at\%) }\end{array}$ & $\begin{array}{c}\text { Binding } \\
\text { energy } \\
(\mathrm{eV})\end{array}$ & $\begin{array}{c}\text { Atomic } \\
\text { percent } \\
(\text { at\% })\end{array}$ & $\begin{array}{c}\text { Binding } \\
\text { energy } \\
(\mathrm{eV})\end{array}$ \\
\hline Acid-MWCNTs & 70.60 & 284.50 & 20.33 & 532.26 & - & - & 3.07 & 169.15 & - & - \\
Co-A-MWCNTs & 84.57 & 284.50 & 11.17 & 531.89 & 2.46 & 781.20 & 1.45 & 169.01 & 0.36 & 400.14 \\
Co-N-MWCNTs & 84.31 & 284.50 & 11.41 & 531.77 & 3.29 & 780.61 & 0.70 & 168.93 & 0.30 & 399.56 \\
\hline
\end{tabular}

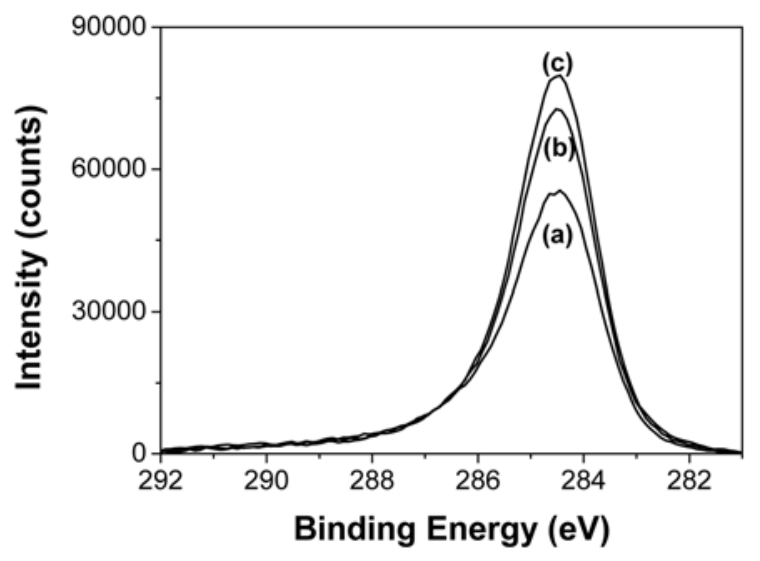

Fig. 4. C1s narrow scan spectra of Acid-MWCNTs (a); Co-AMWCNTs (b); Co-N-MWCNTs (c).

compounds were tightly bonded to carbon on the surface of MWCNTs. Lim et al. reported that SWCNTs were functionalized with thiol groups at the ends of the nanotubes and that the existence of two kinds of carbon-sulfur bonds like $\mathrm{C}=\mathrm{S}$ and $\mathrm{C}-\mathrm{S}$ was characterized by Raman spectra [11]. Cobalt content supported on MWCNTs is linearly proportional to the initial concentration of cobalt precursor solution.

Fig. 4 shows narrow scan spectra of $\mathrm{C} 1 \mathrm{~s}$ peaks of acid treated MWCNTs and cobalt supported MWCNTs. The binding energy of C1s peak for the each sample was 284.5 $\mathrm{eV}$. The change of full width at half maximum (FWHM) for the samples was occurred by reduction process and different precursors. The FWHM values of $\mathrm{C} 1 \mathrm{~s}$ peaks were $1.96 \mathrm{eV}$, $1.82 \mathrm{eV}$ and $1.79 \mathrm{eV}$ as Acid-MWCNTs, Co-A-MWCNTs and Co-N-MWCNTs, respectively.

Fig. 5 showed XPS C1s spectra of acid treated and cobalt supported MWCNTs. As shown in this figure, C1s spectra showed almost symmetric shape. The carbon peaks were obtained in the range of binding energy from 281 to $292 \mathrm{eV}$. The C1s peak of each material was deconvoluted to several Gaussian peaks by peak analysis program obtained from Unipress Co., USA. In the $\mathrm{C} 1 \mathrm{~s}$ peak at $284.5 \mathrm{eV}$, four different peaks obtained at $284.4 \mathrm{eV}, 286.0 \mathrm{eV}, 287.6 \mathrm{eV}$ and $290.1 \mathrm{eV}$, assigned to $\mathrm{C}-\mathrm{C}, \mathrm{C}-\mathrm{O}-\mathrm{R}$ or $\mathrm{C}-\mathrm{NR}_{2}, \mathrm{C}=\mathrm{O}$ and O$\mathrm{C}=\mathrm{O}$, respectively [23]. Thus, it can be concluded that three kinds of functional groups were induced during acid treatment. The result of percent concentration of deconvoluted
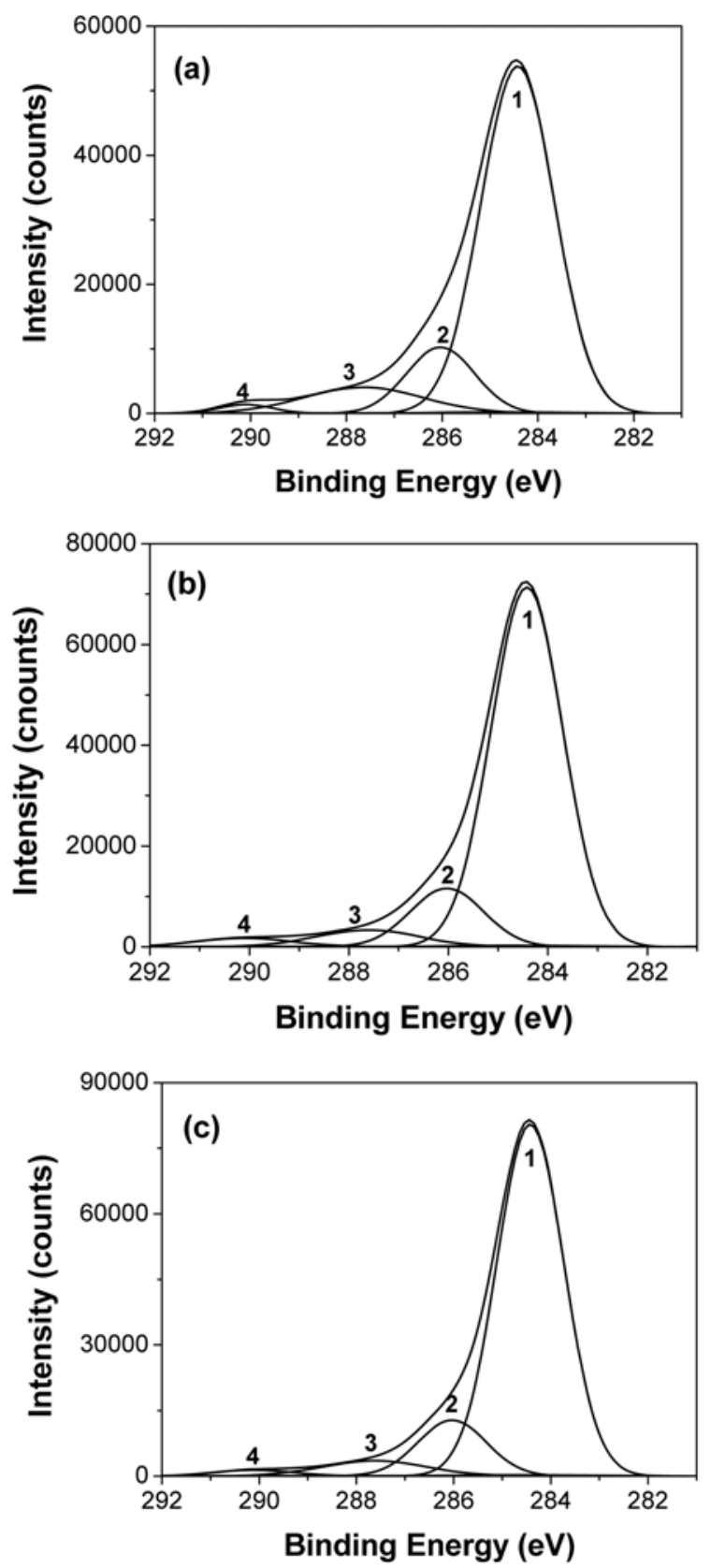

Fig. 5. Deconvolution of the $\mathrm{C} 1 \mathrm{~s}$ peak area into surface functional group; Acid-MWCNTs (a); Co-A-MWCNTs (b); Co-NMWCNTs (c). 


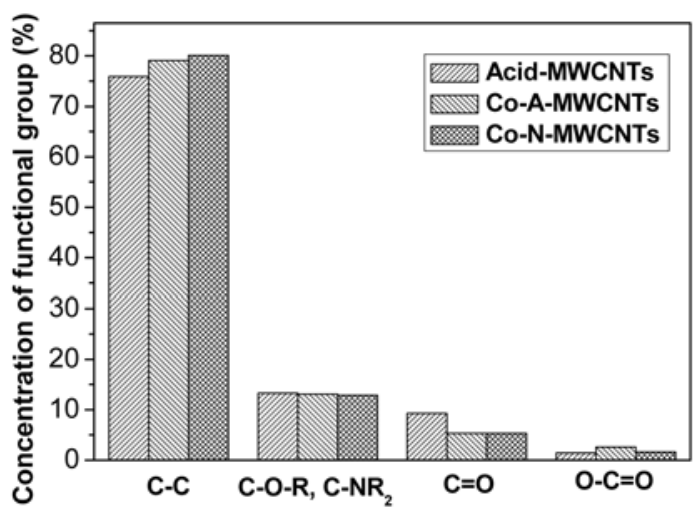

Functional group of $\mathrm{C} 1 \mathrm{~s}$ region

Fig. 6. Surface functional components obtained from the deconvolution of $\mathrm{C} 1 \mathrm{~s}$ peaks.

C1s peak area was shown in Fig. 6. As a result of Table 1, percent concentrations of the $\mathrm{C} 1 \mathrm{~s}$ deconvoluted peak area represented to each functional group, were $75.9 \%(\mathrm{C}-\mathrm{C})$, $13.3 \%\left(\mathrm{C}-\mathrm{O}-\mathrm{R}\right.$ or $\left.\mathrm{C}-\mathrm{NR}_{2}\right), 9.3 \%(-\mathrm{C}=\mathrm{O})$ and $1.4 \%(\mathrm{O}-\mathrm{C}=\mathrm{O})$, respectively. Whereas, the concentration of Co-A-MWCNTs were $79.1 \%(\mathrm{C}-\mathrm{C}), 13.1 \%\left(\mathrm{C}-\mathrm{O}-\mathrm{R}\right.$ or $\left.\mathrm{C}-\mathrm{NR}_{2}\right), 5.3 \%(-\mathrm{C}=\mathrm{O})$ and $2.6 \%(\mathrm{O}-\mathrm{C}=\mathrm{O})$ and the concentration of Co-N-MWCNTs were $80.1 \%(\mathrm{C}-\mathrm{C}), 12.9 \%\left(\mathrm{C}-\mathrm{O}-\mathrm{R}\right.$ or $\left.\mathrm{C}-\mathrm{NR}_{2}\right), 5.3 \%(-\mathrm{C}=\mathrm{O})$ and $1.6 \%(\mathrm{O}-\mathrm{C}=\mathrm{O})$, respectively. As shown in Fig. 6, comparing concentration of $\mathrm{C}=\mathrm{O}$ groups of these samples, $\mathrm{C}=\mathrm{O}$ groups of acid treated MWCNTs were significantly decreased in both Co supported MWCNTs after reduction process.

Fig. 7 showed O1s core level spectra and deconvolution of peak area using Gaussian method. The main peak of all spectra was located at around $532 \mathrm{eV}$. This peak of all spectra attributed to carbon-oxygen single bonding. And the peaks on the highest energy level are carbon-oxygen double

Table 2. O1s peak parameter of acid treated MWCNTs and cobalt supported MWCNTs

\begin{tabular}{lccc}
\hline \multirow{2}{*}{ Sample } & \multicolumn{3}{c}{$\mathrm{O} 1 \mathrm{~s}$} \\
\cline { 2 - 4 } & Lattice $\mathrm{O}^{2-}$ & $\mathrm{C}-\mathrm{O}$ & $\mathrm{C}=\mathrm{O}$ \\
\hline Acid-MWCNTs & & 532.0 & 533.4 \\
Peak position (eV) & - & 2.2 & 2.3 \\
FWHM & - & 59 & 41 \\
Concentration (\%) & - & & \\
\hline Co-A-MWCNTs & & 532.0 & 533.7 \\
Peak position (eV) & 530.1 & 2.3 & 2.7 \\
FWHM & 2.1 & 68 & 20 \\
Concentration (\%) & 12 & & \\
\hline Co-N-MWCNTs & & 531.8 & 533.7 \\
Peak position (eV) & 529.7 & 2.7 & 1.9 \\
FWHM & 1.8 & 76 & 9 \\
Concentration (\%) & 15 & & \\
\hline
\end{tabular}
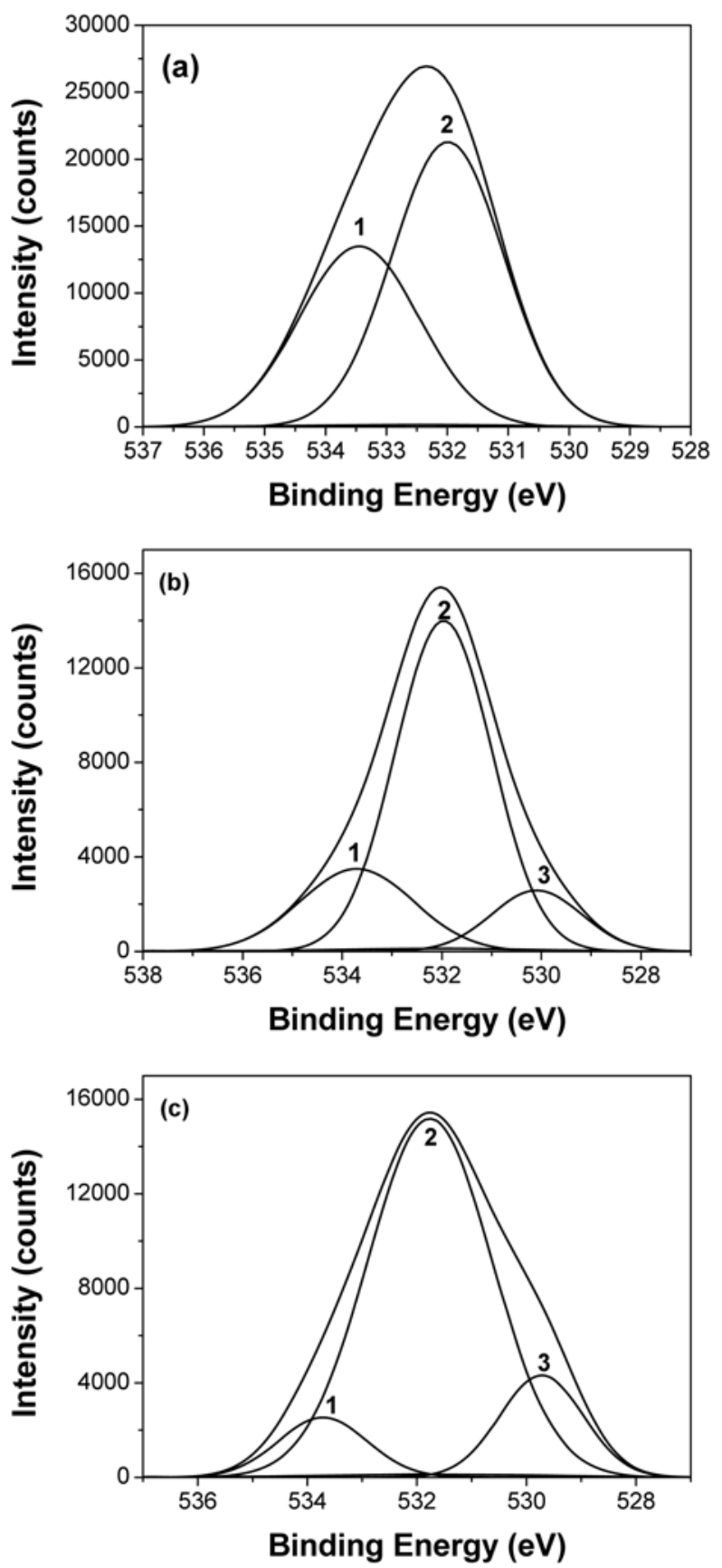

Fig. 7. Deconvolution of the O1s peak area into surface functional group; Acid-MWCNTs (a); Co-A-MWCNTs (b); Co-NMWCNTs (c).

bonding. It is considered that the shoulders at lower one of cobalt supported MWCNTs at approximately $530 \mathrm{eV}$, are lattice $\mathrm{O}^{2-}$ [24]. These peaks suggested that some cobalt on the surface of MWCNTs exist oxide form. Especially, Co-NMWCNTs have $15 \%$ lattice oxygen, which is the higher value than that of Co-A-MWCNTs. The detail deconvolution results of O1s peak were listed in Table 2. 
Table 3. Co2p peak position and Intensity ratio of cobalt supported MWCNTs

\begin{tabular}{lccccc}
\hline \multirow{2}{*}{ Samples } & \multicolumn{3}{c}{ Peak position $(\mathrm{eV})$} & \multicolumn{2}{c}{ Intensity ratio } \\
\cline { 2 - 6 } & $\mathrm{Co} 2 \mathrm{p} 3 / 2$ & $\mathrm{Co} 2 \mathrm{p} 1 / 2$ & Metallic Co & $\mathrm{I}_{\mathrm{C} 2 \mathrm{p} p} / \mathrm{I}_{\mathrm{C} 1 \mathrm{~s}}$ & $\mathrm{ICo} / \mathrm{I}_{\mathrm{C} 1 \mathrm{~s}}$ \\
\hline Co-A-MWCNTs & 781.2 & 797.4 & 778.7 & 0.34 & 0.010 \\
Co-N-MWCNTs & 780.7 & 796.6 & 777.1 & 0.45 & 0.024 \\
\hline
\end{tabular}
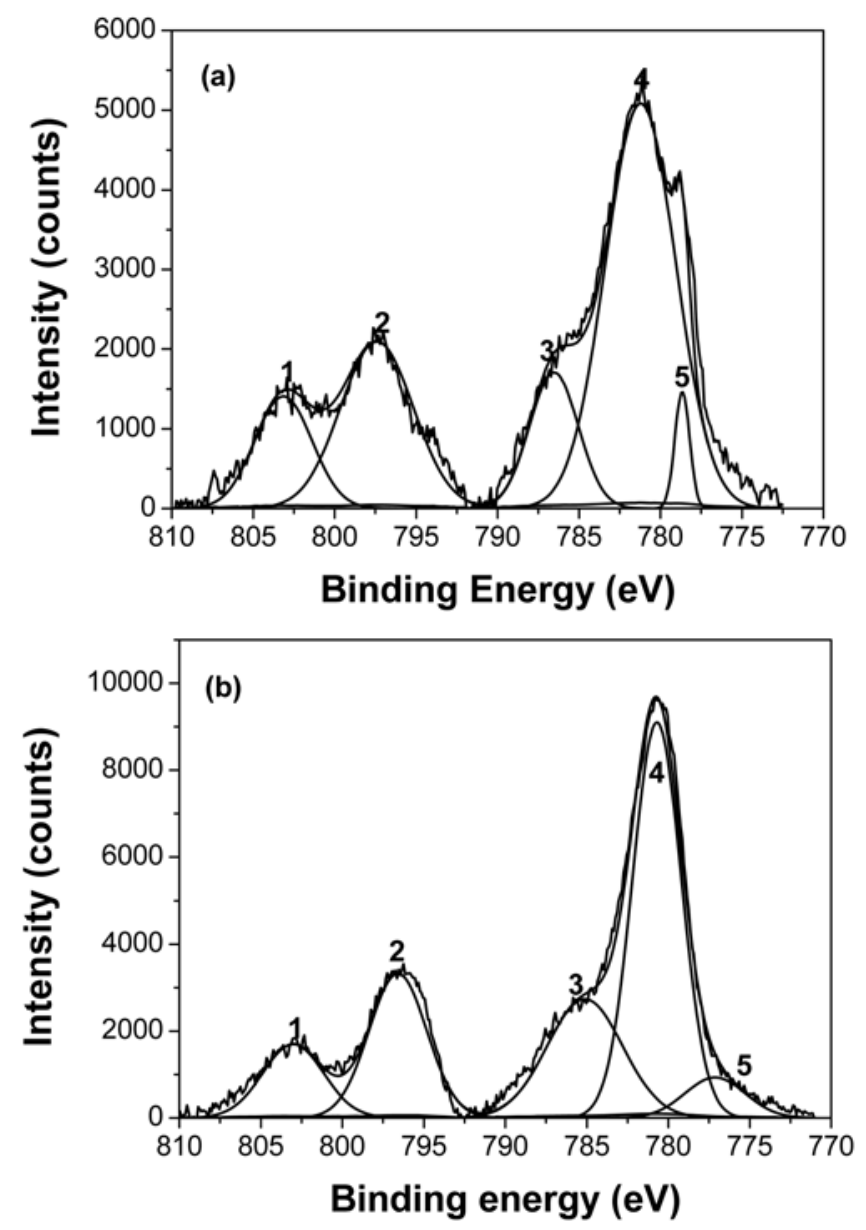

Fig. 8. Deconvolution of the Co2p peak area into surface functional group; Co-A-MWCNTs (a); Co-N-MWCNTs (b).

Fig. 8 showed deconvolution curves of Co2p binding energy range from $770 \mathrm{eV}$ to $810 \mathrm{eV}$ by Gaussian method. As shown in Fig. 8, the peak of (b) obtained from CoMWCNTs decorated with cobalt acetate $\left(\mathrm{Co}\left(\mathrm{CH}_{3} \mathrm{COO}\right)_{2}\right)$ revealed at $778 \mathrm{eV}$. According to the reference [10], this peak may be considered as $\left.\operatorname{Co}\left(\mathrm{C}_{5} \mathrm{H}_{5}\right)\right)_{2}$ or dibuthyldithiocarbamate molecular.

This difference of peak intensity between (a) and (b) was attributed to the cobalt precursor such as cobalt- nitrate and acetate form. As a result listed in Table 3, Co2 $\mathrm{p}_{3 / 2}$ binding energies were $781.2 \mathrm{eV}$ and $780.7 \mathrm{eV}$ corresponding with Co-A-MWCNTs and Co-N-MWCNTs and Co2 $\mathrm{p}_{1 / 2}$ binding energies were 797.4 eV(Co-A-MWCNTs) and 796.3 eV(Co-
N-MWCNTs) respectively. The weak satellites peaks were observed at around $788.6 \mathrm{eV}$ and $803.0 \mathrm{eV}$. This satellites peak is the evidence of presence of $\mathrm{Co}_{3} \mathrm{O}_{4}$ on the surface [25]. The high $\mathrm{I}_{\mathrm{Co2p}} / \mathrm{I}_{\mathrm{C}}$ ratio indicates high dispersion of cobalt on MWCNTs [25]. It is found that cobalt nitrate supported MWCNTs is more dispersive and have catalytic activity than that of cobalt acetate supported MWCNTs at same preparation condition such as concentration of precursor solution and reduction environment.

\section{Conclusion}

The effect of cobalt precursor on the structure of Co supported multi-walled carbon nanotubes (MWCNTs) were studied by using X-ray photoelectron spectroscopy (XPS).

It was found that the cobalt precursor influenced the structure of supported cobalt species. It was shown that decomposition of cobalt nitrate could have higher atomic percent. Judging from O1s peaks, it was suggested that some cobalt particle on the surface of MWCNTs exist oxide form. Especially, Co-N-MWCNTs have $15 \%$ lattice oxygen, which is the higher value than that of Co-A-MWCNTs.

It is found that cobalt nitrate supported MWCNTs is more dispersive and have catalytic activity than that of cobalt acetate supported MWCNTs at same preparation condition such as concentration of precursor solution and reduction environment.

\section{Acknowledgment}

This Research was performed for the Hydrogen Energy R\&D Center, one of the 21 st Century Frontier R\&D Program, funded by the Ministry of Science and Technology of Korea.

\section{References}

[1] Iijima, S. Nature 1991, 354, 56.

[2] Loiseau, A.; Launois, P.; Peit, P.; Roche, S.; Salvetat, J.-P. "Understanding Carbon Nanotubes" Springer, Paris, 2005, 199.

[3] Endo, M.; Dresselhaus, M. "Carbon Nanotubes" Pergmon, New York, 1996, 27. 
[4] Meyyappan, M. "Carbon Nanotubes" CRC Press, California, 2004, 2.

[5] Timothy, D. Burchell "Carbon Materials for Advanced Technologies" Pergmon, York, 1999, 61.

[6] Dillon, A. C.; Jones, K. M.; Bekkedahl, T. A.; Kiang, C. H.; Bethune, D. S.; Heben, M. J. Nature 1997, 386, 377.

[7] Jun, L.; Hou, T. N. "Encyclopedia of nanoscience and nanotechnology" Am. Science Publishers, California, 2004, 591.

[8] Kim, H. S.; Lee, H.; Han, K. S.; Kim, J. H.; Song, M. S.; Park, M. S.; Lee, J. Y.; Kang, J. K. J Phys Chem B. 2005, 109, 8983.

[9] Joo, S. H.; Choi, S. J.; Oh, I.; Kwak, J.; Liu, Z.; Terasaki, O.; Ryoo, R. Nature 2001, 412, 169.

[10] Yoo, E.; Habe, T.; Nakamura, J. Science and Technology of Advanced Materials 2005, 6, 615.

[11] Lim, J. K.; Yun, W. S.; Yoon, M. H.; Lee, S. K.; Kim, C. H.; Kim, K.; Kim, S. K. Synthetic Metals 2003, 139, 521.

[12] Nagatsu, M.; Yoshida, T.; Mesko, M.; Ogino, A.; Matsuda, T.; Tanaka, T.; Tatsuoka, H.; Murakami, K. Carbon 2006, 44, 3336.

[13] Deshpande, R.; Dillon, A. C.; Mahan, A. H.; Alleman, J.; Mitra, S. Thin Solid Films 2006, 501, 216.

[14] Veneza, A. M. Catal. Today 2007, 77, 259.

[15] Naab, F. U.; Dhoubhadel, M.; Gilbert, J. R.; Gilbert, M. C.; Savage, L. K.; Holland, O. W.; Duggan, J. L.; McDaniel,
F. D. Physics Letters A 2006, 356, 152.

[16] Hwang, W.; Mai, G.; Liu, Y.; Yang, C.; Qu, W. J. Nanosci. Nanotechnol. 2004, 4, 423.

[17] Khodakov, A. Y.; Constant, A. G.; Bechara, R.; Zholobenko, V. L. J. Catal. 2002, 206, 230.

[18] Jiang, D.; Zhao, B.; Huang, H.; Xie, Y.; Pan, G.; Ran, G.; Min, E. Appl. Catal. 2000, 192, 1.

[18] Yin, S.-F.; Zhang, Q.-H.; Xu, B.-Q.; Zhu, W.-X.; Ng, C.F.; Au, C.-T. J. Catal. 2004, 224, 384.

[19] Cho, S.-H.; Kim, D.-Y.; Heo, J.-K.; Lee, Y.-H.; An, K.-H.; Kim, S. D.; Lee, Y.-S. Carbon Sci. 2006, 7, 267.

[20] Kim, S. D.; Kim, J. W.; Im, J. S.; Lee, Y. S. J. Disper Sci \& Tech., in press, 2007.

[21] Zhang, H.; Qiu, J.; Liang, C.; Li, Z.; Wang, X.; Wang, Y. Catal. Lett. 2005, 101, 211.

[22] Briggs, D.; Sech, M. P. Practical Surface Analysis; Willy: New York, USA., 1983, 119.

[23] Lee, W. H.; Lee, J. G.; Reucroft, P. J. Appl. Surface Sci. 2001, 171, 136.

[24] Dupin, J. C.; Gonbeau, D.; Moudden, H. B.; Vinatier, P.; Levasseur, A. Thin Solid Film 2001, 384, 23.

[25] Girardon, J. S.; Quinet, E.; Constant, A. G.; Chernavskii, P. A.; Gengembre, L.; Khodakove, J. Catal. Girardon, J. S.; Quinet, E.; Constant, A. G.; Chernavskii, P. A.; Gengembre, L.; Khodakove, J. Catal. 2007, 248, 143. 